\title{
O PHILCARTO COMO FERRAMENTA DIDÁTICA NAS AULAS DE GEOGRAFIA DO ENSINO FUNDAMENTAL
}

\section{The Philcarto as a teaching tool in the geography days of fundamental education}

\author{
Josiane Oliveira de Campos \\ Graduanda em Geografia Licenciatura pela Universidade Federal de Santa Maria (UFSM) \\ Bolsista do Programa de Licenciatura (PROLICEN) \\ josianeoliveira81@hotmail.com
}

Natália Lampert Batista Doutoranda em Geografia pelo PPGGeo da Universidade Federal de Santa Maria (UFSM). Professora de Geografia na Escola Municipal de Ensino Fundamental J/AO CAIC 'Luizinho de Grandi' natilbatista3@gmail.com

Roberto Cassol

Doutor em Geografia (Geografia Humana) pela Universidade de São Paulo (USP, 1996). Professor titular doutor da Universidade Federal de Santa Maria (UFSM) nos cursos de graduação em Geografia presencial e a distância e na Pós-Graduação em Geografia robertocassol@gmail.com

Maurício Rizzatti Mestrando em Geografia pelo Programa de Pós-Graduação em Geografia (PPGGeo) da Universidade Federal de Santa Maria (UFSM) geo.mauricio.rizzatti@gmail.com

\begin{abstract}
RESUMO: As geotecnologias e os softwares livres voltados à espacialização de dados geográficos emergem como um campo de investigação e de qualificação da educação básica que precisa ser explorado e debatido enquanto possibilidade metodológica do ensino de Geografia. Assim, o presente projeto teve como objetivo despertar o interesse dos alunos do Ensino Fundamental para processo de ensino-aprendizagem por meio de geotecnologias, utilizando o software livre Philcarto, no mapeamento de indicadores sociais brasileiros. Para isso, desenvolveu-se a sequência didática constituida de quatro encontros didáticos, onde os alunos produziram e interpretaram mapas sobre indicadores sociais brasileiros. O projeto contribuiu com a aprendizagem dos alunos por meio de geotecnologias e os instigou a compreender o conteúdo trabalhado de forma mais eficiente e significativa.
\end{abstract}

Palavras-chave: Cartografia Escolar; Ensino de Geografia; Sequência Didática.

ABSTRACT: Geotechnologies and free softwares geographic data spatial emergence as a field of research and qualification of basic education that needs to be explored and debated as a methodological possibility of teaching Geography. Thus, the present project had as objective to awaken the interest of elementary school students for teaching-learning process through geotechnologies, using the free software Philcarto, in the mapping of Brazilian social indicators. For that, a didactic sequence was 
O PHILCARTO COMO FERRAMENTA DIDÁTICA NAS AULAS DE GEOGRAFIA DO ENSINO FUNDAMENTAL

developed consisting of four didactic meetings, where students produced and interpreted maps on Brazilian social indicators. The project contributed to students' learning through geotechnologies and instigated them to understand the content worked in a more efficient and meaningful way.

Keywords: School Cartography; Geography Teaching; Sequence teaching.

\section{INTRODUÇÃO}

$\mathrm{Na}$ atual sociedade da informação, o computador está cada vez mais inserido no cotidiano dos alunos, bem como os smartphones com acesso à internet, sendo que estes equipamentos estão ligados ao uso de mapas e ao Sistema de Posicionamento Global (GPS). Essa realidade pode ser observada, por exemplo, nos inúmeros aplicativos e redes sociais que permitem check-ins (dizer onde se está por meio de um mapa) e atrela a comunicação à localização espacial e ressaltam a necessidade de desenvolver competências e as habilidades vinculadas a Cartografia Escolar para conduzir aos usuários a leitura e confecção crítica dos mapas que circulam livremente na rede mundial de computadores (RIZZATTI et al, 2017).

Com base nessa observação, destaca-se que as geotecnologias são importantes ferramentas para o ensino de Geografia no século XXI, pois dinamizam as aulas e tornam o conteúdo geográfico mais atrativo para os estudantes que estão cada vez mais imersos na realidade virtual e as tem como elo entre sua vida real e a construção de saberes necessários à atuação social nos dias de hoje. Desse modo, o uso dessas ferramentas acaba por se tornar quase que obrigatório no ambiente escolar, como forma de motivação dos alunos frente ao ensino de Geografia.

Assim, o presente artigo é um recorte do projeto "Geotecnologias na escola: mapeando indicadores sociais brasileiros com alunos do Ensino Fundamental", financiado pelo Programa de Licenciaturas, da Universidade Federal de Santa Maria (UFSM) que teve como objetivo geral despertar o interesse dos alunos do Ensino Fundamental para o ensino-aprendizagem por meio de geotecnologias, utilizando o software livre Philcarto no mapeamento de indicadores sociais brasileiros ${ }^{1}$.

${ }^{1}$ Conteúdo de Geografia previsto pelo Currículo municipal no $7^{\circ}$ ano do Ensino Fundamental. 
O PHILCARTO COMO FERRAMENTA DIDÁTICA NAS AULAS DE GEOGRAFIA DO ENSINO FUNDAMENTAL

\section{REVISTA GEONORTE}

Especificamente se objetivou: mapear indicadores sociais brasileiros, com estudantes da Educação Básica, como faixas de etárias e sexo da população, concentração no campo e/ou na cidade, produção econômica regional; correlacionar indicadores sociais em diferentes escalas, a saber, o Município, o Estado, as Regiões do Instituto Brasileiro de Geografia e Estatística (IBGE) e o País; verificar a compreensão dos alunos frente às temáticas mapeadas; e identificar se os alunos se motivaram ao trabalhar com recursos geotecnológicos na construção de conhecimentos geográficos.

\section{GEOTECNOLOGIAS NA ESCOLA: O QUE ESCREVEM OS AUTORES?}

O mundo passou por significativas transformações ao longo dos últimos vinte anos e o ser humano necessita acompanhar tais mudanças, pois elas emergem como novos desafios nas mais diversas esferas do agir humano. Seja no trabalho, na aprendizagem ou na diversão, as tecnologias se fazem presentes e exigem o domínio desse novo código de comunicação.

Dessa maneira, a educação é um dos setores que necessita se (re)adaptar para dar conta das mudanças sociais que implicam em novas formas de aprender dos estudantes. Os professores se veem desafiados a receber essas tecnologias, aprender utilizá-las e reorganizar suas metodologias didáticas para possibilitar que o aluno compreenda os conteúdos trabalhados em aula de forma mais inovadora e mais interativa.

A Geografia, neste contexto, é uma das áreas do conhecimento que pode ser muito beneficiada por essas inovações tecnológicas na apresentação e na sistematização das aulas na Educação Básica, ou seja, as novas geotecnologias constituem elementos didáticos que podem contribuir para a melhoria nas aulas de Geografia em razão de que fazem ligação com quase todas as outras áreas do conhecimento científico e auxiliam a produção de aulas multidisciplinares e integradoras (CAVALCANTE; BIESEK, 2009) e, por conseguinte, mais interessantes e atrativas. 
O PHILCARTO COMO FERRAMENTA DIDÁTICA NAS AULAS DE GEOGRAFIA DO ENSINO FUNDAMENTAL

Neste sentido, as geotecnologias podem ser facilitadoras para o entendimento da Cartografia Escolar e, consequentemente, dos assuntos da Geografia (LEME, 2015). O mapa está inegavelmente presente no cotidiano de todos, como destacam Paiva e Leite (2015), e por isso é tão importante estar inserido no processo de ensinoaprendizagem de Geografia.

Assim,

\begin{abstract}
O uso dessas ferramentas pode aproximar alunos e professores, além de ser útil na exploração dos conteúdos de forma mais interativa. O aluno passa de mero receptor, que só observa e nem sempre compreende, para um sujeito mais ativo e participativo. E o objetivo principal de todo esse processo é tornar o aluno capaz de desenvolver seu trabalho, torná-lo o autor e o professor apenas o ajuda na condução desse processo de construção. (MEDEIROS; ARAÚJO, 2013, p. 8).
\end{abstract}

A partir disso, é preciso explorar as diversas possibilitadas geradas pelas geotecnologias no ensino de Geografia, visando permitir que o aluno consiga aprender de forma participativa e interativa, desafiando-lhe a resolver problemas concretos e, por conseguinte, a aprender significativamente. A exemplo disso, a utilização de softwares livre em sala de aula e no mapeamento das realidades conhecidas dos estudantes permite que eles se motivem e se interessem pelo que se está sendo discutido ampliando, assim, a capacidade de desenvolver habilidades que provoquem a reflexão e a autonomia na construção dos conhecimentos geográficos.

Nas aulas de Geografia, especialmente, é indispensável citar e aprofundar o estudo dos mapas e das representações gráficas, pois segundo Joly (2004, p. 9), "dentro dos limites das restrições de um contexto, o mapa descreve uma porção do espaço geográfico com suas características qualitativas e/ ou quantitativas", ou seja, os mapas são a amostra visual do que se pretende ensinar em sala de aula e isso é de suma relevância para professores que querem e buscam ofertar aulas dinâmicas visando à aprendizagem dos estudantes.

As realidades das escolas brasileiras nem sempre dão conta da inserção de tecnologias complexas e revolucionárias, todavia, de posse em um laboratório de informática com internet é possível diversificar as linguagens utilizadas e permitir com que o aluno interaja com os softwares capazes de contribuir com sua aprendizagem. 
O PHILCARTO COMO FERRAMENTA DIDÁTICA NAS AULAS DE GEOGRAFIA DO ENSINO FUNDAMENTAL

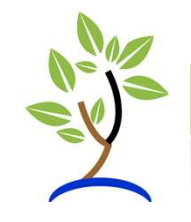

Uma possibilidade pedagógica inovadora e que pode tornar as aulas de Geografia interessantes e diversas é o Philcarto. Desenvolvido pelo geógrafo francês Philippe Waniez, trata-se de um software livre que pode ser obtido na página do autor na internet ${ }^{2}$.

O software conta com versão em nove idiomas, como apresenta a Figura 1, dentre elas a língua portuguesa. A partir do Philcarto, os educandos podem elaborar diversos mapas temáticos: mapas de setor, de figuras proporcionais, coropléticos, pontos de contagem, entre outros. Além disso, o programa apresenta recursos cartográficos e estatísticos, que podem ser explorados pelos professores e pelos alunos, incorporando (novas e mais complexas) análises aos conhecimentos geográficos trabalhados (FRANCA; LIMA; RIBEIRO, 2011). Cabe ressaltar que segundo a Licença para utilização do Philcarto para Windows ${ }^{\circledR}$, na publicação do mapa elaborado com o software se deve apresentar que foi "Elaborado com Philcarto: http://philcarto.free.fr" e que todos os direitos de propriedade e autorais frente ao Philcarto são de Philippe Waniez.

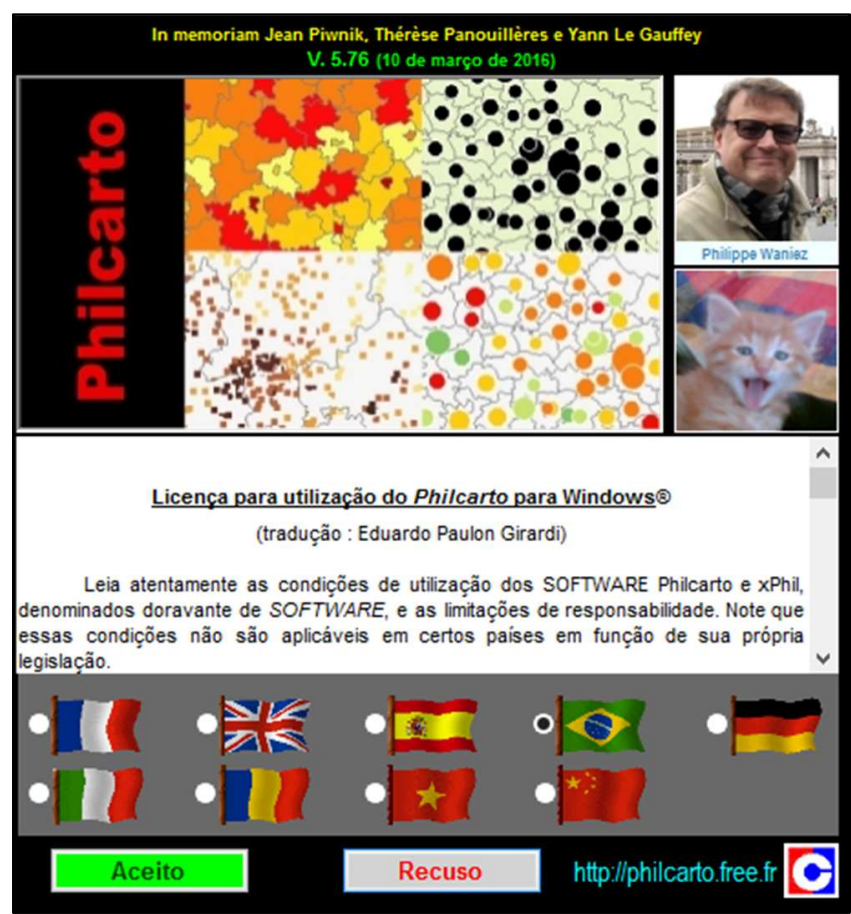

Figura 1: Interface inicial do software Philcarto.

Fonte: <http://philcarto.free.fr/>, acesso em setembro de 2017.

2Link de acesso ao software: <http://philcarto.free.fr/>, acesso em setembro de 2017. 
O PHILCARTO COMO FERRAMENTA DIDÁTICA NAS AULAS DE GEOGRAFIA DO ENSINO FUNDAMENTAL

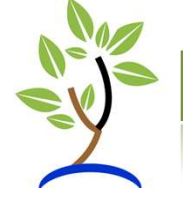

$\mathrm{Na}$ confecção de um mapa temático no Philcarto, por exemplo, pode-se representar qualquer fenômeno que apresente uma característica espacial, logo, a preocupação central no mapeamento deve ser o tema representado e a qualidade da representação desse tema. Assim, segundo Nogueira (2009), na Cartografia Temática, os temas a serem mapeados são muito variados, por isso, a construção de cada mapa temático é sempre um desafio e precisa mostrar claramente o que, onde e como ocorre determinado fenômeno geográfico.

Para a qualidade de um mapa temático, os dados representáveis devem se basear nas variáveis visuais, também conhecidas como perceptivas ou de retina, e expressar uma das três relações básicas (de qualidade, de quantidade ou de ordem), sendo apresentadas por um modo de implementação especifico (ponto, linha e área), como apresenta a Figura 2.

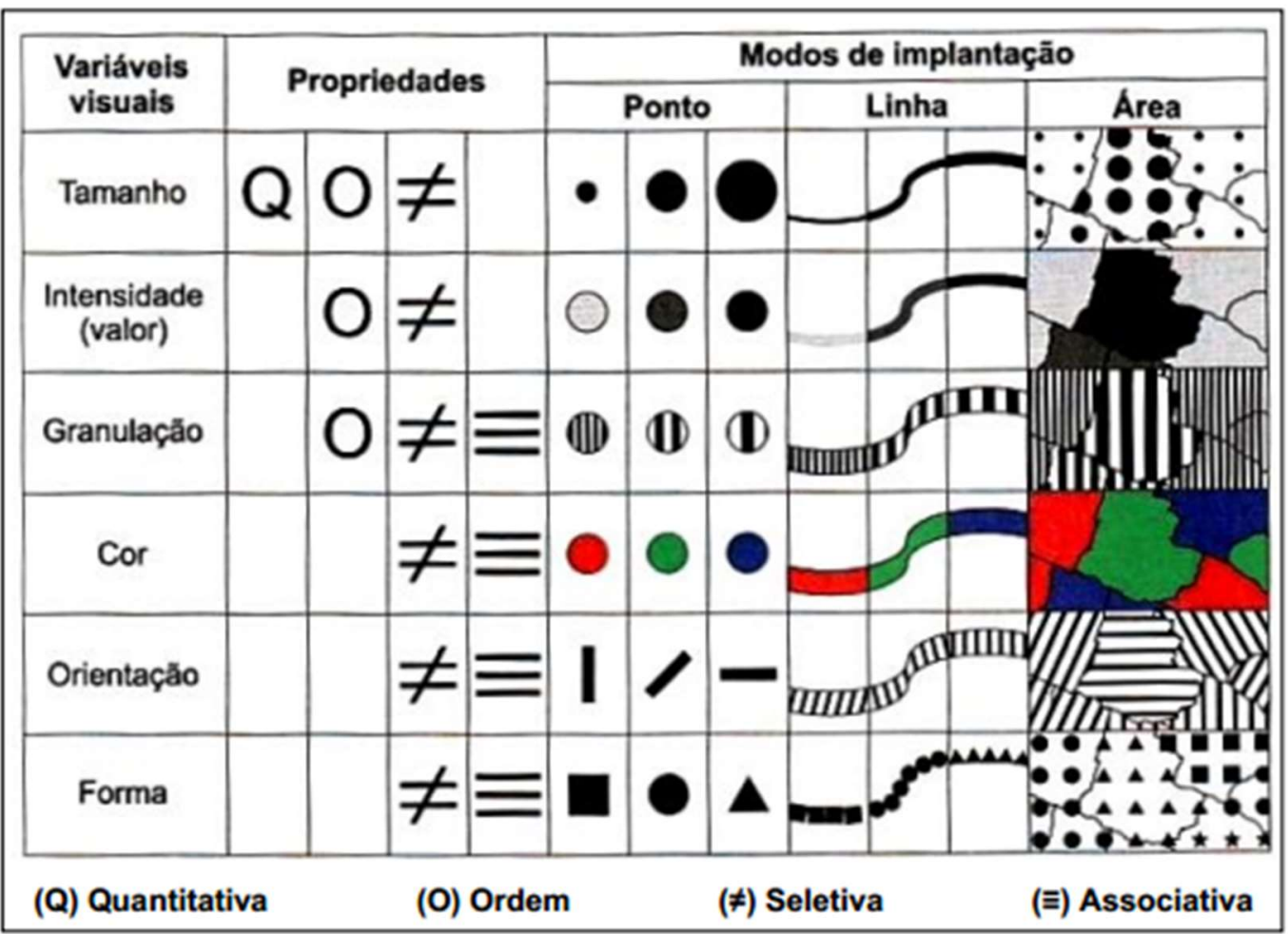

Figura 2: Propriedades Visuais dos mapeamentos temáticos. Fonte: RAMOS, 2005, p. 23 citando Cardoso, 1984, p. 42. 
O PHILCARTO COMO FERRAMENTA DIDÁTICA NAS AULAS DE GEOGRAFIA DO ENSINO FUNDAMENTAL

Sobre esse assunto, Martinelli (2001, p. 07) destaca que

[...] os mapas temáticos podem ser construídos, levando-se em conta vários métodos; cada um mais apropriado às características e às formas de manifestação (em pontos, em linhas, em áreas) dos fenômenos da realidade considerados em cada tema seja na abordagem qualitativa, ordenada ou quantitativa. Podemos empreender também uma apreciação sob o ponto de vista estático, constituindo a cartografia estática, ou dinâmica, estruturando a cartografia dinâmica.

As abordagens apontadas por Martinelli (2001) foram sintetizadas, com base em Mantovani (s/d), no Quadro 1.

Quadro 1: Relações Básicas da Cartografia Temática.

\begin{tabular}{|l|l|}
\hline Representações Qualitativas $(\nexists)$ & $\begin{array}{l}\text { "São empregadas para expressar a existência, a } \\
\text { localização e a extensão das ocorrências dos fenômenos } \\
\text { ou de suas categorias que se diferenciam pela sua } \\
\text { natureza ou tipo, podendo ser classificadas por } \\
\text { determinados critérios. Abordam a ocorrência sem } \\
\text { considerar a intensidade da manifestação, no entanto } \\
\text { podem ser colocadas, se for de interesse, em uma ordem } \\
\text { lógica" (MANTOVANI, s/d, p. 6). }\end{array}$ \\
\hline Representações Ordenadas (O) & $\begin{array}{l}\text { "São indicadas quando as categorias dos fenômenos se } \\
\text { inscrevem numa sequência única e universalmente } \\
\text { admitida. A relação entre objetos é de ordem" } \\
\text { (MANTOVANI, s/d, p. 6). }\end{array}$ \\
\hline Representações Quantitativas (Q) & $\begin{array}{l}\text { "São empregadas para evidenciar a relação de } \\
\text { proporcionalidade entre objetos. Esta relação deve ser } \\
\text { transcrita por relações visuais de mesma natureza" } \\
\text { (MANTOVANI, s/d, p. 6). }\end{array}$ \\
\hline
\end{tabular}

Fonte: Mantovani, s/d, p. 6.

Neste sentido, no presente projeto predominaram representação quantitativas ao destacar faixas de etárias e sexo da população, concentração no campo e/ou na cidade, pessoas responsáveis, cônjuges, filhos(as) e enteados(as), netos(as) e Bisnetos(as), ou seja, quantidade de pessoas por área representada, e qualitativas ao mapear produção econômica regional, isto é, o que se produz em cada lugar. Para esses mapeamentos, utilizaram-se os métodos de representação cartográfica classificados, de com Martinelli (2003), em: 
O PHILCARTO COMO FERRAMENTA DIDÁTICA NAS AULAS DE GEOGRAFIA DO ENSINO FUNDAMENTAL

- Pontos de contagem: no qual se expressa uma variação do número de pontos iguais pela área de ocorrência e sua concentração indica maior presença do fenômeno;

- Distribuição regular de pontos de tamanho crescentes: apresenta a variação do tamanho dos pontos distribuídos na área;

- Figuras geométricas proporcionais: dá-se pela variação de tamanho de um símbolo na área de abrangência do fenômeno;

- Isarítmico: usa-se isolinhas preenchendo o espaço entre elas, pois apresenta valor igual;

- Coroplético: apresenta uma série de valores visuais preestabelecidos e associados à propriedade perceptiva cor.

Nesta perspectiva, o uso de geotecnologias no mapeamento temático pode ser muito interessante no contexto do ensino de Geografia e proporcionar aprendizagens mais dinâmicas para os estudantes, pois na atualidade "os mapas se desmaterializaram, passaram não apenas a serem produzidos por meio de computadores, como também são feitos para circularem no espaço das redes", (CANTO, 2016, p. 755) isso possibilita a diversificação de recursos geotecnológicos no ensino e a inovação pedagógica em sala de aula. Além do mais, estudos já realizados analisaram e aprovam a eficiência de softwares livres, como o Philcarto, no processo de ensino-aprendizagem.

Como apontam Franca, Ribeiro e Lima (2011), o Philcarto é de alta contribuição para o ensino da Geografia nas instituições educacionais e escolas, pois

O princípio básico de funcionamento do Philcarto é o cruzamento de uma base de dados com uma base cartográfica, ambos livremente elaborados pelo usuário do programa. A base cartográfica é elaborada com o programa Phildigit, também de autoria de Waniez, que aceita qualquer tipo de imagem como mapa. A conexão entre os dados e a base cartográfica é realizada pelo Philcarto através de códigos atribuídos às unidades espaciais nessas duas bases. A partir desta junção são elaborados os mapas e realizadas diferentes análises estatístico-espaciais pelo programa por meio de uma interface interativa e fácil (FRANCA; RIBEIRO; LIMA, 2011, p. 166). 
O PHILCARTO COMO FERRAMENTA DIDÁTICA NAS AULAS DE GEOGRAFIA DO ENSINO FUNDAMENTAL

Portanto, o uso das geotecnologias nas escolas gera a motivação por parte dos alunos, porque desperta a curiosidade pela temática proposta e porque insere elementos midiáticos atuais como sugerem os Parâmetros Curriculares Nacionais (PCNs) (BRASIL, 1998). Por esses motivos, mais do que nunca, as geotecnologias, como ferramentas de ensino, emergem como um campo de investigação e de qualificação da educação básica que precisa ser explorado e debatido enquanto possibilidade teórica e metodológica do ensino de Geografia.

\section{GEOTECNOLOGIAS NA ESCOLA: A PRÁTICA EM SALA DE AULA}

Com base nas teorias norteadoras apresentadas, a atividade proposta foi dividida em quatro encontros, com duração média de 50 minutos cada, com quatro turmas de $7^{\circ}$ ano $^{3}$ da Escola Municipal de Ensino Fundamental Junto ao CAIC Luizinho de Grani, localizada no Bairro Lorenzi, no município de Santa Maria, RS (Figura 3). Cada encontro foi ministrado através de aplicação de questionário, reflexões, contextualização e trabalho de mapeamento com software Philcarto visando à compreensão e integração dos alunos, pois:

O aluno deve se sentir parte integrante de todo o processo de ensinoaprendizagem e, ao construir um mapa, ele estará participando de forma direta da elaboração. Além desta aproximação da realidade da prática cartográfica, é de considerável valor a apreensão da sua realidade com dados referentes ao seu convívio, com elaboração de mapas de seu bairro, seu município e outros recortes que ele tenha maior aproximação (FRANCA; RIBEIRO; LIMA, 2011, p. 170).

\footnotetext{
${ }^{3}$ As quatro turmas $\left(7^{\circ}\right.$ ano verde, $7^{\circ}$ ano azul, $7^{\circ}$ ano amarelo e $7^{\circ}$ ano laranja) tinham aulas de Geografia na terça-feira de manhã (um período de 55 minutos cada). Assim, aplicou-se a mesma atividade com cada turma no seu período, totalizando quatro encontros com cada um dos grupos de alunos.
} 
O PHILCARTO COMO FERRAMENTA DIDÁTICA NAS AULAS DE GEOGRAFIA DO ENSINO FUNDAMENTAL

\section{REVISTA GENORTE}

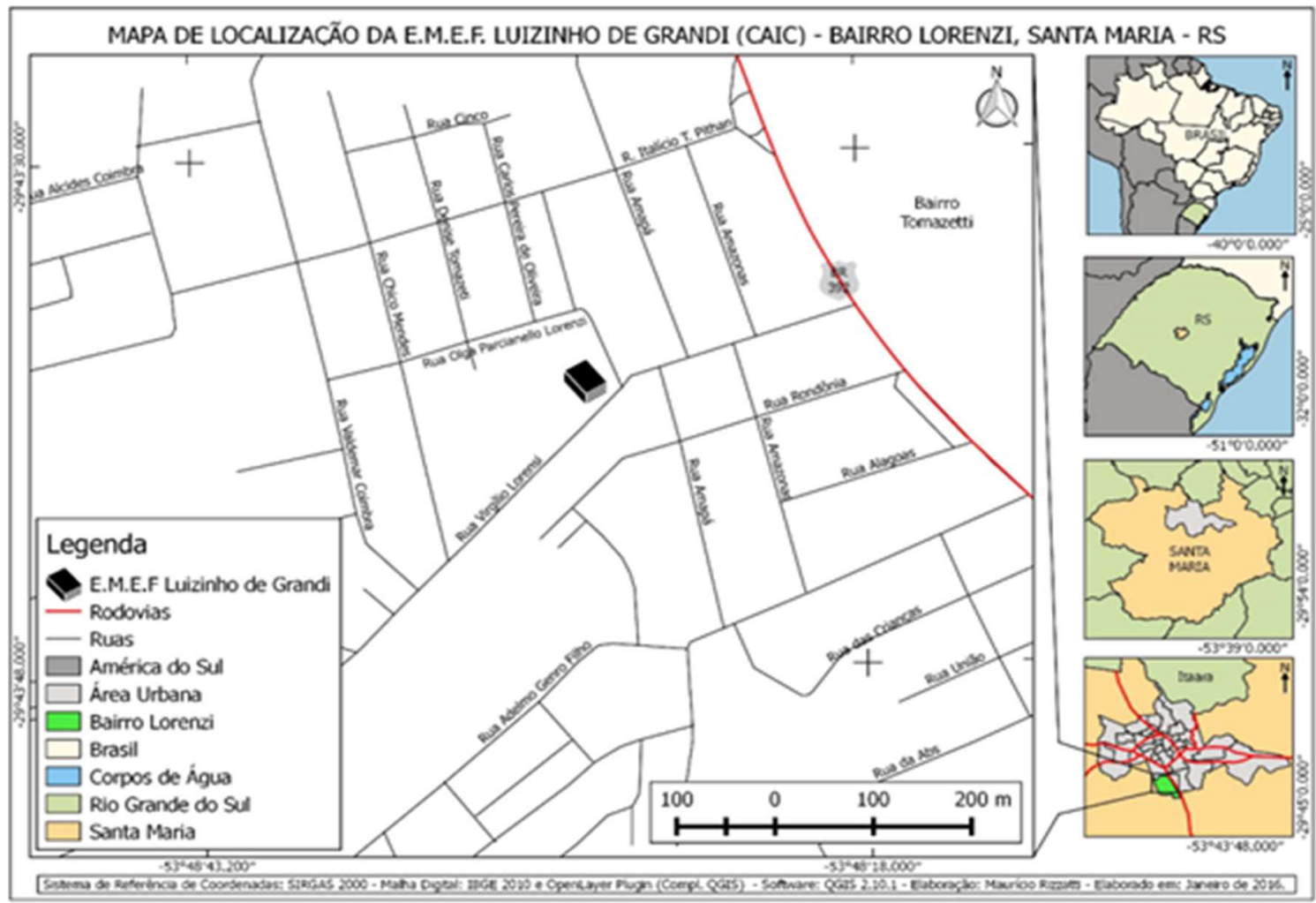

Figura 3: Mapa de localização da EMEF J/AO CAIC "Luizinho de Grandi”.

Elaboração: Maurício Rizzatti (2016).

O encontro inicial foi realizado com o viés de aproximação entre a bolsista e os alunos, bem como a introdução do assunto que foi trabalhado ao longo do projeto, uma vez que para muitos dos educandos a temática era algo totalmente novo (Figura 4). Tendo em vista ser o primeiro contato com a turma foi indispensável também realizar uma apresentação da teoria (relacionada ao conteúdo programático da série em questão) sobre o projeto que seria desenvolvido. 


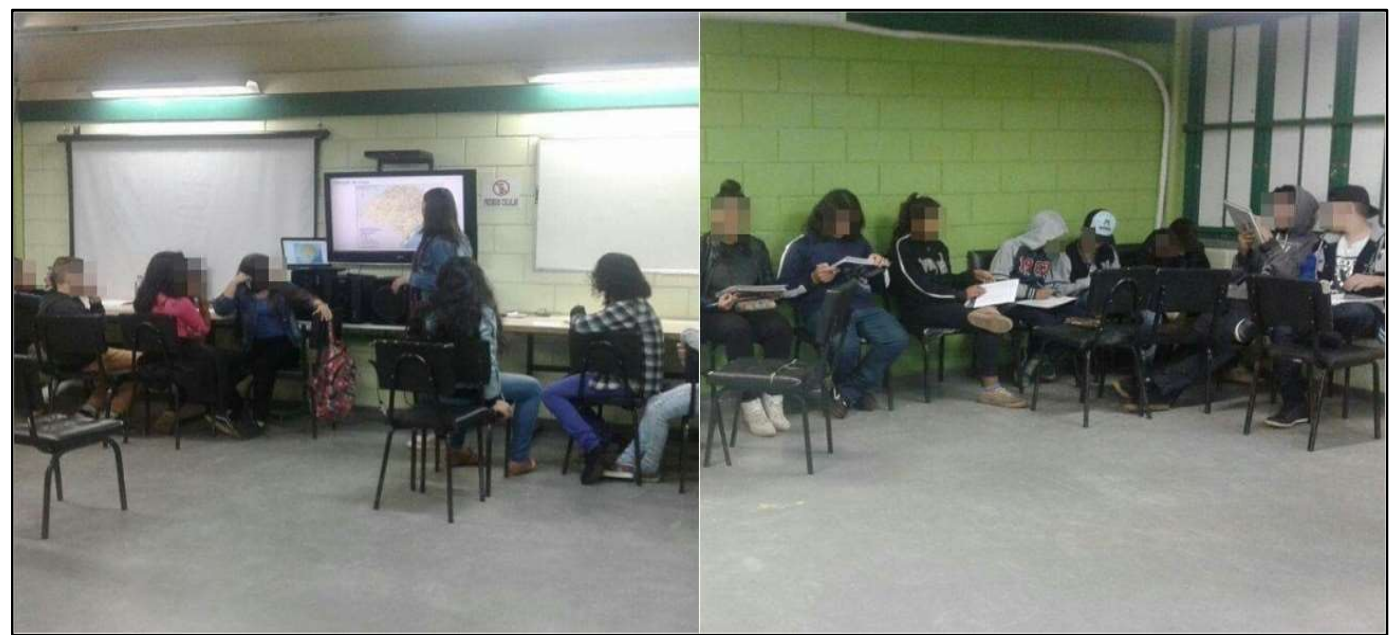

Figura 4: Primeiro encontro com os alunos. Fonte: Atividade na escola, 2017.

Então, se fez uma breve apresentação sobre o que é o Philcarto e sobre suas possibilidades de uso na Geografia. Posteriormente, foi aplicado um questionário para conhecer as práticas de interação tecnológica dos alunos, bem como verificar sua familiaridade ou não com as tecnologias. O questionário foi aplicado às quatro turmas de $7^{\circ}$ ano da escola, $7^{\circ}$ verde (13 alunos), $7^{\circ}$ laranja (17 alunos), $7^{\circ}$ amarelo (18 alunos) e $7^{\circ}$ azul (16 alunos) ${ }^{4}$.

Observou-se que os alunos possuem em média 12 e 14 anos e que a maioria dos discentes (67\%) têm contatos com as tecnologias diariamente o que ressalta que elas estão presentes na vida dos jovens e permite inferir que esse contato frequente facilitou a interação com o software Philcarto, bem como para a motivação dos estudantes com a proposta metodológica. Todavia, 70\% dos discentes apontaram não possuir acesso à internet em seu domicílio e a utilizam na casa de amigos e na escola.

Tratando da finalidade do uso desses recursos, percebe-se que predomina o uso para o lazer (55\%), especificamente, para acessar o WhatsApp e o Facebook. Cerca de $28 \%$ dos alunos responderam usar as tecnologias para várias funções, integrando estudo e lazer e 17\% utilizam apenas para estudar. Essa interface demostrou que o uso dos recursos ainda é limitado e, por isso, o projeto pode mostrar-

\footnotetext{
${ }^{4}$ Ressalta-se que o questionário foi aplicado no dia 23 de maio de 2017 e que o número de alunos apresentado corresponde aos respondentes e não ao número total de alunos por turma. Todas as turmas possuem cerca de 20 alunos matriculados.
} 
O PHILCARTO COMO FERRAMENTA DIDÁTICA NAS AULAS DE GEOGRAFIA DO ENSINO FUNDAMENTAL

Ihes novas finalidades de uso de tecnologias, fazendo-os se interessaram por dados geográficos que lhes pareciam difíceis e complexos nas tabelas presentes nos livros didáticos e consultados no IBGE.

Dessa maneira, por gostarem de utilizar tecnologias e considerarem importantes para sua vida pessoal e para a sua aprendizagem, $72 \%$ evidenciam que gostariam de usá-las em sala de aula e que elas facilitam a sua aprendizagem. Portanto, fica nítido que a utilização de geotecnologias na sala de aula é cada vez mais necessária e que contempla a realidade e os desejos dos estudantes, motivandoos e despertando o interesse deles pelo processo de ensino-aprendizagem.

Na segunda aula, iniciou-se a prática de mapeamento, buscando de forma didática e pausadamente introduzir conhecimentos referentes à espacialização de indicadores sociais brasileiros com o Philcarto. Pensando em deixar o encontro mais dinâmico e interativo, foi permitido que os educandos formassem trios para iniciar o manuseio do software, bem como para que pudessem auxiliar os colegas com dificuldades em trabalhar com as novas tecnologias.

Primeiramente, foi apresentado o software, informações referentes ao seu autor e de como o programa chegou ao Brasil. Em seguida foi feita uma breve explicação sobre como é possível fazer download do programa, destacando-se o site oficial do programa: <http://philcarto.free.fr/s. E também sobre como é realizada construção do Banco de Dados utilizado para a espacialização das informações. Após, os alunos foram convidados a mapear os seguintes indicadores sociais: Faixas de etárias, Sexo da População, Concentração da população no campo, Concentração da população na cidade, Produção econômica para o Brasil e suas regiões segundo o IBGE: Sul, Sudeste, Centro-Oeste, Nordeste e Norte.

Conforme os alunos foram desenvolvendo os mapas, foram induzidos a explorar outras ferramentas do software como os diferentes tipos de mapa e alteração das cores. No encerramento da aula os mapas foram "salvos" no computador da escola. Assim, no $2^{\circ}$ encontro os alunos adquiriram noções básicas referentes ao mapeamento e a utilização do software. 
O PHILCARTO COMO FERRAMENTA DIDÁTICA NAS AULAS DE GEOGRAFIA DO ENSINO FUNDAMENTAL

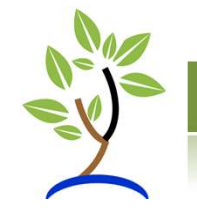

No terceiro encontro, trabalharam-se como escalas mais próximas: o Estado (Rio Grande do Sul) e o município de Santa Maria (RS). Após os alunos foram desafiados a correlacionar os indicadores sociais trabalhados nas diferentes escalas geográficas, ou seja, destacaram quais as semelhanças e diferenças entre as Regiões do Brasil, o Estado e o Município que residem e estudam. A Figura 5 demostra a interação de alguns alunos com o programa de mapeamento.

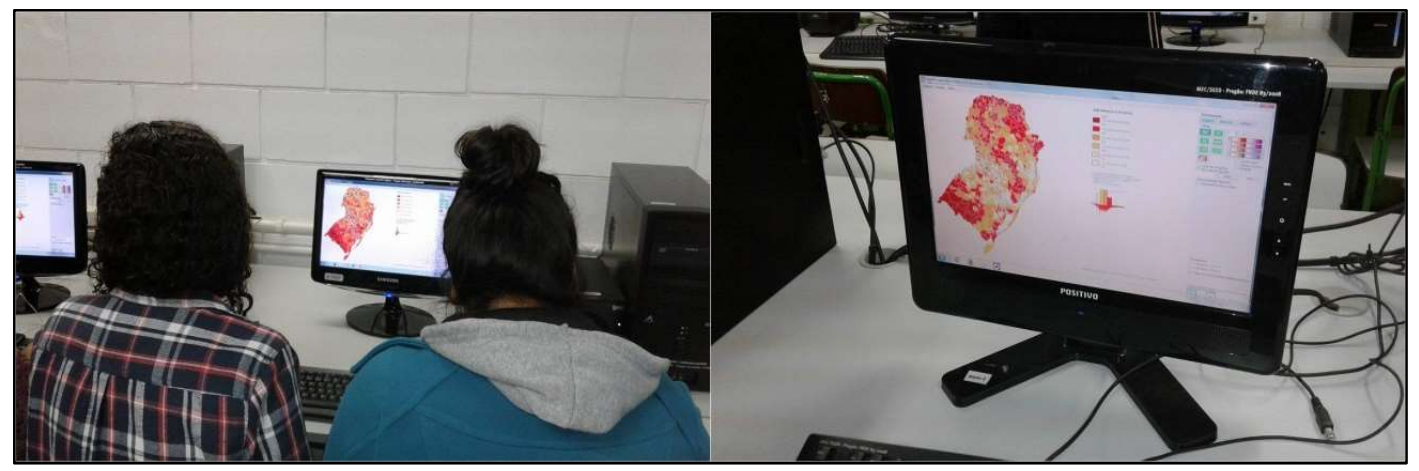

Figura 5: Segundo encontros com os alunos. Fonte: Atividade na escola, 2017.

Os alunos se sentiram motivados e perguntaram intensamente durante toda a aula o que evidenciou a eficiência do programa como ferramenta pedagógica no ensino de Geografia, bem como destacaram que é mais fácil e divertido compreender os indicadores sociais, por meio dos mapas construídos por eles (Figura 6), no computador. 


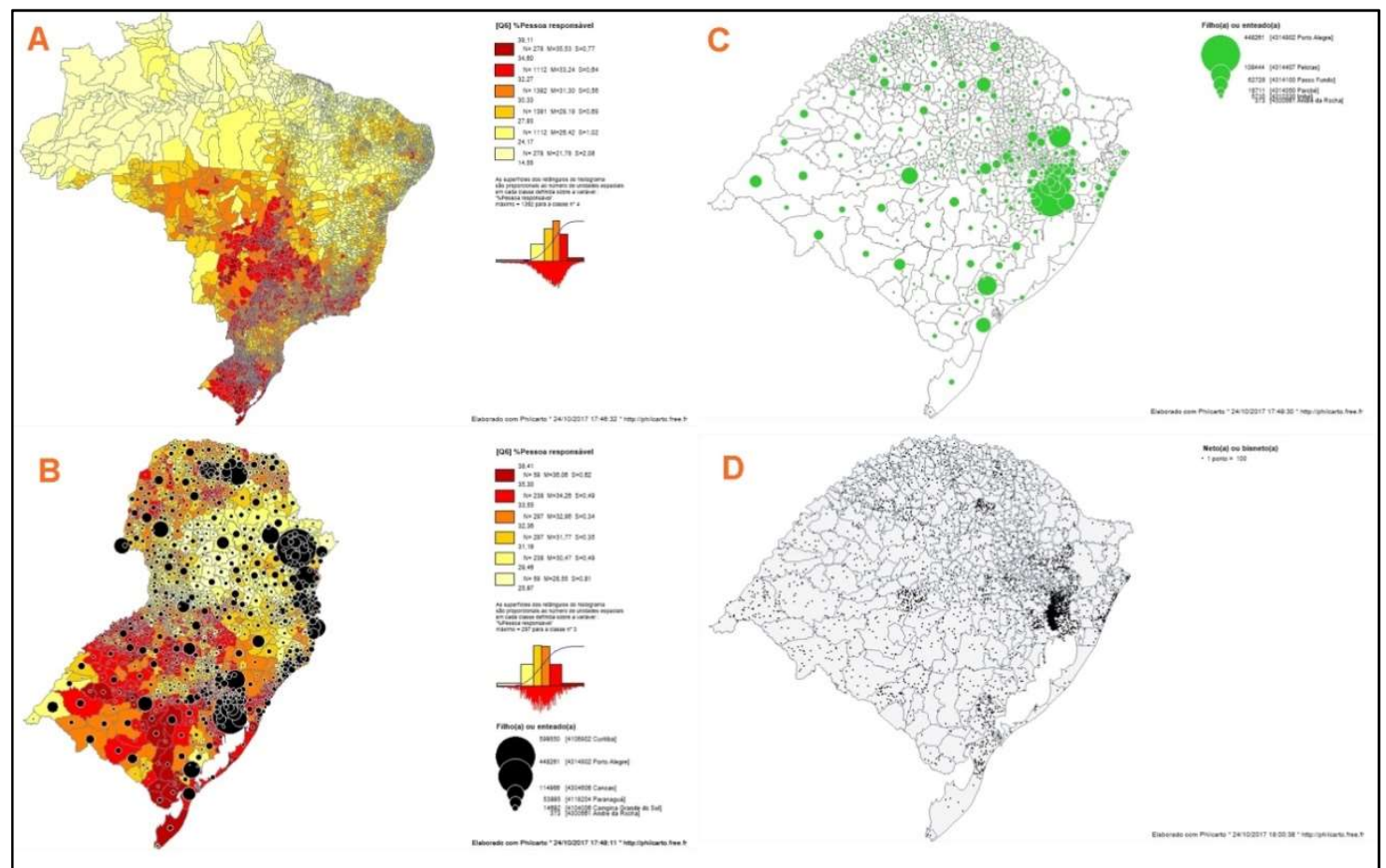

Figura 6: Exemplos de mapas temáticos elaborados pelos alunos: a) Coroplético sobre População Responsável; b) Coroplético e Figuras Proporcionais para População Responsável e Número de Filhos(as) ou Enteados(as), respectivamente, sobrepostos; c) Figuras Proporcionais para número de Filhos(as) ou Enteados(as); e d) Pontos de Contagem para Neto(a) e Bisneto(a). Os mapas foram confeccionados primeiramente por afinidade do estudante, após alterou-se, quando necessário, o método de representação para espacializar melhor o fenômeno em análise. Fonte: Mapas produzidos por alunos no Philcarto, 2017.

No último encontro, foram visualizados os mapas elaborados pelos estudantes e relembraram-se as discussões que haviam sido realizadas nas aulas anteriores. Posteriormente, os estudantes foram convidados a relatarem como perceberam as atividades desenvolvidas ao longo do projeto (Figura 7). Todos evidenciaram a sua satisfação com a prática empreendida e demostraram terem construído conhecimentos sobre o tema abordado e sobre o processo de mapeamento. 
O PHILCARTO COMO FERRAMENTA DIDÁTICA NAS AULAS DE GEOGRAFIA DO ENSINO FUNDAMENTAL

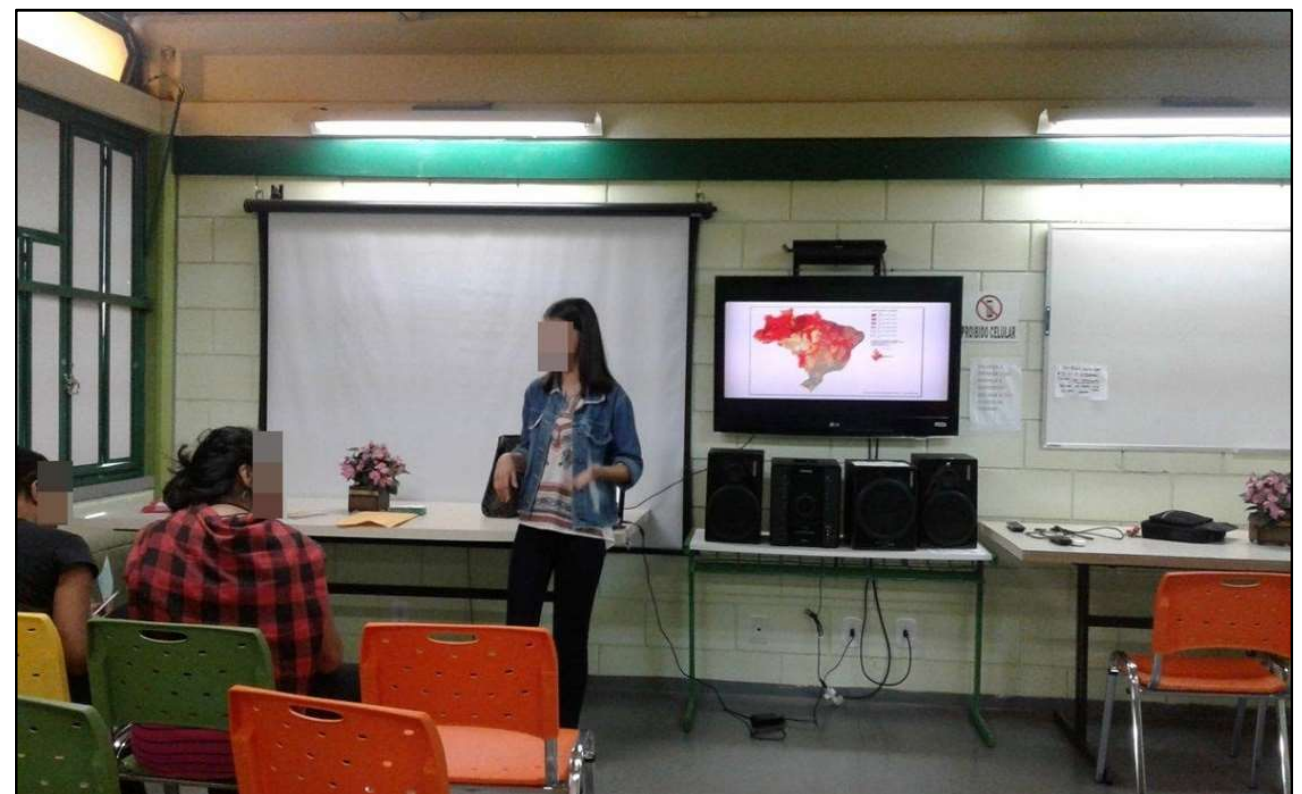

Figura 7: Quarto encontro com os alunos. Fonte: Atividade na escola, 2017.

Após isso, desenvolveu-se uma dinâmica de finalização do projeto. Primeiramente, foi projetado em Power Point o mapa do Brasil construído por um dos educandos e os mesmos foram desafiados a mostrar/dizer aproximadamente aonde é a localização do município de Santa Maria (RS), bem como tecer uma interpretação sobre o indicador social (População Responsável) presente no mapeamento. Após, cada aluno ganhou um mapa (havia oito tipos de mapas diferentes na sala) e teve que escrever qual a escala do mapa (municipal, estadual, regional ou nacional) e qual indicador social o mesmo estava mapeando, além de explicar o que poderia ser observado na representação gráfica, conforme evidência a Figura 8. Os alunos que acertarem pelo menos um dos quesitos solicitados ganharam como prêmio um pirulito.

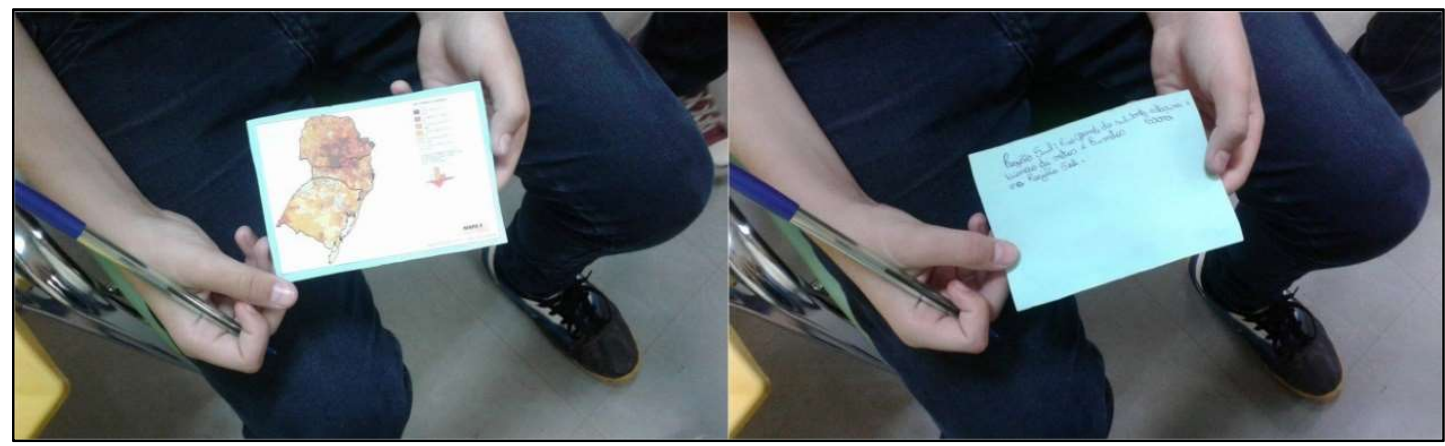

Figura 8: Dinâmica Final do Projeto. Fonte: Atividade na escola, 2017. 
O PHILCARTO COMO FERRAMENTA DIDÁTICA NAS AULAS DE GEOGRAFIA DO ENSINO FUNDAMENTAL

\section{CONCLUSÃO}

Como mencionado no decorrer do artigo, as geotecnologias emergem como ferramentas didáticas de grande contribuição ao ensino de Geografia, porque possibilitam integrar recursos motivadores com práticas pedagógicas inovadoras e que contribuem com a aprendizagem significativa dos estudantes. Dessa forma, as atividades que foram propostas aos alunos durante os quatro encontros, envolveram os estudantes, fazendo-os interagir com os dados geográficos, com os colegas e com os educadores na contrução do conhecimento geográfico.

Logo, o projeto contribuiu com a aprendizagem dos alunos e os instigou a compreender o conteúdo trabalhado de forma mais eficiente, demostrando que o software Philcarto, ao ser utilizado nas aulas de Geografia, para o mapeamento de indicadores sociais brasileiro, é capaz de despertar o interesse dos alunos do Ensino Fundamental para o ensino-aprendizagem por meio de geotecnologias. Além disso, o software possibilita mapear diferentes indicadores sociais em diferentes escalas de análise, gerando debates sobre a realidade do País. Portanto, a proposta didática se mostrou eficiente para trabalhar o conteúdo geográfico do $7^{\circ}$ ano do Ensino Fundamental e colaborou para a construção de conhecimentos dos estudantes.

\section{REFERÊNCIAS}

BRASIL, Ministério da Educação e Cultura. Secretaria da Educação. Parâmetros Curriculares Nacionais. MEC/SEF; 1997.

CANTO, T. S. O mapa como linguagem líquida: novas possibilidades para a Cartografia Escolar In: IX Colóquio de Cartografia para Crianças e Escolares, Goiânia, 2016.

CAVALCANTE, M. M. A; BIESEK, A. S. O uso de Tecnologia no Ensino de Geografia: experiência na formação de professores. In: $1^{\circ}$ Encontro Nacional de Práticas no Ensino de Geografia, Porto Alegre, 2009.

DIONÍSIO, A. P; LEITE, S. Mapas (Série Caderos de Sugestão Didáticas). Recife: Pipa Comunicações, 2015. 
O PHILCARTO COMO FERRAMENTA DIDÁTICA NAS AULAS DE GEOGRAFIA DO ENSINO FUNDAMENTAL

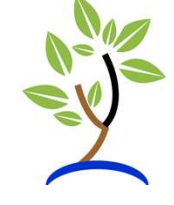

FRANCA, R.R; RIBEIRO, A. F. A; LIMA, J. H; Software Philcarto: Uma ferramenta para o uso da linguagem cartográfica digital na escola. In: Geonordeste, Ano XXIII, n. 2, p. 162-178, jan./jun. 2012.

JOLY, F. A cartografia. São Paulo: Papirus, 1990.

LEME, A. M. Utilização de Cartografia e Geotecnologias para o Ensino de Geografia: Experiências do Projeto GEOENCART. Trabalho de Conclusão de Curso (Graduação em Geografia). Rio Claro, SP: Universidade Estadual Paulista "Júlio de Mesquita Filho", 2015.

MANTOVANI, A. C. M. M. Reflexões sobre o ensino de cartografia temática na Geografia. Disponível em: <http://www.cartografia.ime.eb.br/artigos/epq2.pdf>, acesso em outubro de 2017.

MARTINELLI, M. Mapas da Geografia e Cartografia Temática. São Paulo: Contexto, 2003.

MARTINELLI, M. Os Mapas na Geografia. 2001. Disponível em: <http://www2.fct.unesp.br/docentes/geo/girardi/Cartografia\%20PPGG\%202015/TEX TO\%2001.pdf>, acesso em outubro de 2017.

MEDEIROS, A. P. A; ARAÚJO, S. K. O Uso de Ferramentas Tecnológicas na Sala de Aula. In: XX EGEORN, Natal, 2013.

NOGUEIRA, R. E. Cartografia: representação, comunicação e visualização de dados espaciais. 3. ed. Florianópolis: Ed. da UFSC, 2009.

RAMOS, C. S. Visualização cartográfica e cartografia multimídia: conceitos e tecnologias. São Paulo: Editora UNESP, 2005.

RIZZATTI, M; CASSOL, R; BATISTA, N. L; DAMBROS, G. Utilização de Geotecnologias na Cartografia Escolar: a compreensão da representação do relevo com alunos do Ensino Fundamental. In: Geografia em Questão (Online), v. 10, p. 56-76, 2017.

Submetido em: 29/09/2017

Aceito para publicação em: 26/10/2017 